\title{
Executing a Scharnow turn: reconciling shipping emissions with international commitments on climate change
}

Carbon Management (2012) 3(6), 615-628

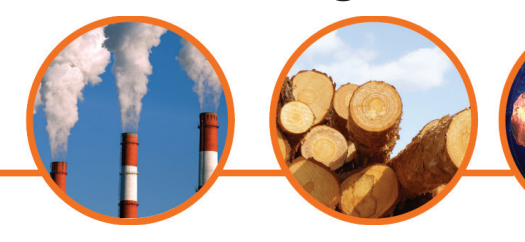

\begin{abstract}
Kevin Anderson*1 \& Alice Bows ${ }^{2}$
The Copenhagen Accord (and Cancun Agreement) commits the international community to "hold the increase in global temperature below $2^{\circ} \mathrm{C}$, and take action to meet this objective consistent with science and on the basis of equity." This article explores the implications of these commitments for the shipping sector. It outlines how the science of climate change places stringent constraints on the sector's emissions at the global level while the equity dimension tightens still further the industry's emissions space for the Annex 1 nations. The mitigation potential of proposed global-scale measures are detailed and the apportionment of emissions between non-Annex 1 and Annex 1 discussed. Building on the scientific framing of cumulative emissions, the article concludes that nothing short of an immediate 'Scharnow turn' is necessary if the industry is not to capsize wider efforts to "hold the increase in global temperature below $2^{\circ} \mathrm{C}^{\prime}$.
\end{abstract}

"The Scharnow turn is a maneuver used to bring a ship or boat back to a point it previously passed through and is most appropriate when the point to be reached is significantly further astern than the vessel's turning radius."

US Coast Guard 2010 [1]

In 2011, a year of economic recession and upheaval for many industrialized nations, global $\mathrm{CO}_{2}$ emissions rose by $3.2 \%$ from the 2010 figure, which itself was up almost $6 \%$ on 2009 [2]. It is against such a backdrop of significant and escalating growth in emissions that the mitigation efforts of all sectors, including international aviation and shipping, are coming under increasing scrutiny. There is a mounting recognition that if "stabilization of GHG concentrations in the atmosphere at a level that would prevent dangerous anthropogenic interference with the climate system" is to remain a serious goal of the international community, these two important sectors will not be exempt from delivering absolute and proportionate reductions in emissions [3].

This paper focuses expressly on emissions from international shipping. The analysis develops from a literal reading of high-level statements characterizing the threshold between acceptable and dangerous climate change, with a similarly precise interpretation of commitments made on mitigation at the global, subglobal and, with regards to shipping, the sectoral level. The paper directly translates the language of climate change obligations into a quantitative framing of absolute reductions in emissions, along with accompanying rates of mitigation. In so doing, and with just one now unavoidable exception (see the global context below), the analysis makes no attempt to assuage political or industrial sensibilities. Instead, it proceeds through the sequential logic of commitments on climate change from the international community, the International Chamber of Shipping (ICS) and the International Maritime Organization (IMO), to provide scientifically informed, evidence-based and internally coherent mitigation pathways for the industry.

The principal framing of this paper is consistent with the International Energy Agency's (IEA's) Energy Outlook 2011 [4] and the subsequent and bleak assessments by both the IEA's Chief Executive (Maria van der Hoeven) [101] and their Chief Economist (Faith Birol) [5]:

"The current state of affairs is unacceptable ... Energyrelated $\mathrm{CO}_{2}$ emissions are at historic highs, and under

'Tyndall Centre for Climate Change Research, School of Mechanical, Aerospace \& Civil Engineering, University of Manchester, Manchester, M13 9PL, UK

${ }^{2}$ Sustainable Consumption Institute, School of Mechanical, Aerospace \& Civil Engineering, University of Manchester, Manchester, M13 9PL, UK

*Author for correspondence: Tel. +44 161306 3701; E-mail: kevin.anderson@manchester.ac.uk 


\section{Key terms}

International shipping: Shipping

activity associated with internationa

trade.

Cumulative emissions: Build up of GHG emissions in the atmosphere.

Carbon budget: Quantity of cumulative emissions related to a particular future temperature rise. current policies, we estimate that energy use and $\mathrm{CO}_{2}$ emissions would increase by a third by 2020, and almost double by 2050. [This] trend is perfectly in line with a temperature increase of $6^{\circ} \mathrm{C}$, which would have devastating consequences for the planet."

Previously, but in similar vein to the concerns expressed by the IEA, the then Secretary-General of the IMO (Efthimios E Mitropoulos), in an impassioned message marking World Maritime Day (2009), offered an uncompromising assessment of the challenges facing the global community [6]:

"Mankind is on the horns of a dilemma. For, whether we like it or not, our collective way of life has become unsustainable and we need to do something about it - and soon. The choices we have made about the way we lead our lives have been slowly eating away at the very support system that enables us to live and breathe. This cannot, and should not, go on. We need to make some tough decisions, we need to make them now and we need to act on them as one, with total and undivided commitment - today and in the future. Faced with facts we cannot argue against, we need to consider our priorities and accept that we have to make certain sacrifices; we need to start putting 'life' ahead of 'lifestyle."

It is against this backdrop of rapidly escalating emissions, mounting anxiety over the accompanying impacts and express commitments to prevent dangerous interference with the climate system that this paper considers the role and responsibility of international shipping.

The analysis proceeds through the seven sections, and includes a suite of quantified mitigation pathways for shipping and a numerical appraisal of how these compare with the best endeavors for emission reductions proposed by the industry.

The global context

The international community, through Article 2 of the UNFCCC, commits to the "stabilization of GHG concentrations in the atmosphere at a level that would prevent dangerous anthropogenic interference with the climate system" [3]. However, it was not until the 2009 Copenhagen Accord that there was international agreement as to what quantitatively constituted 'dangerous interference' and from which clear global levels of mitigation could be robustly developed. The Accord stipulates that collectively the global community should "hold the increase in global temperature below $2^{\circ} \mathrm{C}$, and take action to meet this objective consistent with science and on the basis of equity" [7]. While a relatively simple statement, the Accord reflects similar commitments expressed previously at more regional and national levels $[8,9]$ and later as part of the Cancun Agreement.

The framing of $2^{\circ} \mathrm{C}$ as 'at or below', 'do not exceed', 'hold below', 'must rise no more than' and other similar language, all imply a high chance of it not being exceeded (the $2^{\circ} \mathrm{C}$ figure is relative to preindustrial levels, with, in $2012,0.8^{\circ} \mathrm{C}$ of that rise having already occurred). Translating this qualitative language of chance into quantitative probabilities enables cumulative emissions budgets to be derived $[10,11]$. The greater the chance of remaining below $2^{\circ} \mathrm{C}$, the smaller the quantity of emissions (carbon budget) that can be released during the 21st century. It is in making this translation from probabilities to budgets that an exception to the literal reading of commitments informing the remainder of this paper is made. As it stands, and despite continued high-level statements to the contrary, the emissions released since the start of the millennium have already made it probable that the $2^{\circ} \mathrm{C}$ of warming will be exceeded. Consequently, and using the IPCC 'likelihood scale' of probabilities, the analysis within this paper is premised on a highly conservative reading of to "hold ... below $2^{\circ} \mathrm{C}$ " [12]. Although the commitment enshrined in the Accord aligns with an 'exceptionally unlikely' (1\%) to 'very unlikely' (10\%) probability of exceeding $2^{\circ} \mathrm{C}$, the reality of emissions in 2012 leaves the international community with, at best, 'about as likely as not' (33-66\%) chance of $2^{\circ} \mathrm{C}$.

In 2011, Anderson and Bows developed suites of emission pathways for $\mathrm{CO}_{2}$ commensurate with a range of probabilities of exceeding the $2^{\circ} \mathrm{C}$ threshold [10]. Building on updated versions of these energyonly emission budgets, this paper adopts two global budgets of energy-related $\mathrm{CO}_{2}$ emissions, both of which sit within the IPCC's 'about as likely as not' range. Moreover, both assume highly optimistic reductions in emissions from deforestation and around a halving of current non- $\mathrm{CO}_{2}$ emissions/capita from food production by 2050 . The first budget offers a $37 \%$ chance of exceeding $2^{\circ} \mathrm{C}$ and equates to approximately $1320 \mathrm{GtCO}_{2}$ between 2000 and 2100 . The second is less constrained, with a $50 \%$ chance of $2^{\circ} \mathrm{C}$ and an accompanying budget of approximately $1580 \mathrm{GtCO}_{2}$. These cumulative values based on Macintosh [13] relate to the emission pathways of Anderson and Bows [10]; however, in practice it should be considered as a guide to approximate budgets that relate to an approximately 40 and $50 \%$ chance of staying below $2^{\circ} \mathrm{C}$.

These proposed budgets are, as noted, premised on a highly conservative reading of international (and many national) commitments around $2^{\circ} \mathrm{C}$. As such, the accompanying levels of mitigation are significantly 
reduced from those that would accompany a more literal translation. It is this background of already weakened international resolve that the commitments from the shipping sector are now considered.

\section{Shipping's headline commitments on climate change}

The IMO and the ICS are, respectively, the UN regulatory agencies responsible for shipping and the "principal international trade association for merchant ship operators" (covering $~ 80 \%$ of the world's merchant fleet [102]). Within this section, the headline positions of both the IMO Secretariat and ICS on the shipping industry's role in mitigating emissions are considered; these are later contrasted with the detailed analysis provided by various IMO reports (particularly the Second IMO GHG Study 2009 [14] and the 2011 Assessment of the IMO Mandated Energy Efficiency Measures [15]). Where statements are attributed to the IMO, these hereafter relate to the Secretariat and do not necessarily accord with the views of its 170 members.

The shipping industry has a well-established and often-cited view that the regulatory preserve of international shipping should reside solely with the IMO, exempt from any national or regional interference. The IMO Secretariat asserts not only that " $[\mathrm{T}]$ he overarching logic of the international shipping industry requires an international regulatory regime," but that it is "imperative" that such "regulation should, without exception, be the responsibility of an international body exclusively dealing with maritime matters" [16]. It proceeds to note that, with the requisite skills and experience, it (the IMO) is "uniquely placed" to deliver on broader climate change objectives. The ICS echo this position, with the Secretary-General stating, "it is imperative [the] IMO [be left] to consider and provide the right answers at the right time - without any external pressure on the organization" [17]. Moreover, the ICS attest to there being strong support among ship owners for "global rules for a global industry", and that applying regionally specified rules would lead to "chaos, inefficiency and serious market distortion" [18].

The ICS provide still further clarification as to their recommendations for regulating the industry when they note how shipping resembles a "sovereign nation" and, hence, does not lend itself to "inclusion in national $\mathrm{CO}_{2}$ reductions targets," but instead requires a "special global regime for shipping" [19]. Although outside of the IMO and ICS, there is a range of proposals from different shipping-related organizations as to the specific instruments for controlling emissions (e.g., the report by shipping organizations across the UK, Australia, Sweden, Norway and Belgium [20], and the long list of proposals for market-based measures submitted to the
IMO [21]), the notion of a "special global regime for shipping" exempt from national or regional interference remains pivotal to them all.

Given the shipping industry's vigorous defense of the IMO having exclusive control of the sector's emissions, the question arises as to what role do the IMO and ICS envisage shipping has in delivering international commitments to reduce emissions. As the SecretaryGeneral of the IMO stressed, there is an urgent need for "tough decisions" and "total and undivided commitment" in responding to the challenges of climate change; a position supported by the Chairman of the ICS when he declared that, "The ultimate goal of the shipping industry is simple: zero accidents, zero loss of life and zero pollution" [19]. More specifically, both the IMO and the ICS are adamant that the "shipping industry is committed to playing its part in further reducing its $\mathrm{CO}_{2}$ emissions," and that this "must be proportionate to shipping's share of the total global emissions (less than 3\%)" [103]. This issue of shipping's share of the mitigation effort is commonly evoked by the industry, most notably in submissions to the UNFCCC where, for example, the IMO make clear that the sector "will make its fair and proportionate contribution towards realizing the objectives that this Conference [Durban 2011] and the global community pursue" [22]. The ICS go further and suggest the industry's $\mathrm{CO}_{2}$ emission reductions "should be at least as ambitious as the $\mathrm{CO}_{2}$ emissions reduction agreed under any new UNFCCC" [23].

Quantifying mitigation objectives for shipping Bringing together high-level statements on climate change by the international community, with those from the IMO and ICS on behalf of shipping, points to a sequential logic of commitments from which a quantifiable emission-reduction pathway for shipping can be derived. The following list summarizes the headline statements detailed earlier:

- The international community has committed to work together to "prevent dangerous anthropogenic interference with the climate system";

- The Copenhagen Accord and Cancun Agreements define a warming of $2^{\circ} \mathrm{C}$ as the appropriate threshold between acceptable and dangerous climate change;

- 141 global nations (representing $90 \%$ of total global emissions) have either signed or expressed their intention to be listed as agreeing to the Copenhagen Accord;

- The IMO has announced that the shipping industry "will make its fair and proportionate contribution" to meet internationally agreed levels of mitigation; 


\section{Key terms}

No more favorable treatment:

Maritime principal to treat all ships equally.

Common but differentiated responsibility: Differential treatment of nations with regard to climate change targets depending on their economic development.
- The ICS reiterates how the industry's mitigation "must be proportionate to shipping's share of global emissions";

- The ICS and IMO argue for there to be a "special global regime for shipping" whereby it be subject to regulation as if it were a sovereign nation;

- The ICS declare that mitigation from the sovereign nation of shipping will "be at least as ambitious" as those agreed under the UNFCCC.

Taking these statements as a genuine reflection of the concerns and intentions of the industry, the IMO and ICS affirm that the level of mitigation from shipping will be at least equivalent to that required of a typical sovereign nation in delivering approximately $50 \%$ probability of avoiding $2^{\circ} \mathrm{C}$ of warming. Having established this as a clear objective of the industry and building on the discussion previously it is possible to develop a quantified emission pathway for the industry.

Before proceeding to construct such pathways, there is a pivotal refinement to the IMO principle of 'no more favorable treatment for ships' that needs to be considered. Presently, all IMO regulations, once ratified are, de facto, applied equally to all ships regardless of the flag of registration or nation of ownership, for example (apart from if a ship operates only in those waters outwith the jurisdiction of nations that have ratified the particular regulation/convention). In contrast with this principle, but in line with the Kyoto principle of 'common but differentiated responsibility' (CBDR), some nations (China, Indian and Brazil among them) have argued that mitigation effort should only be demanded of the Annex 1 nations, with non-Annex 1 nations exempt from control. While there may be merit for and against this position, and certainly it is an area of major discussion within the IMO, this article treats 'no favorable treatment' and 'differentiated responsibility' as equally legitimate, with quantitative analysis developed for both positions. However, in relation to CBDR, the suggestion that non-Annex 1 shipping should be exempt from significant control needs to be adjusted in line with the aggregate constraints on emissions accompanying $2{ }^{\circ} \mathrm{C}$ budgets and pathways. Given the quantity of emissions released between 2000 and 2012, emissions budgets and pathways for an 'as likely as not' chance of staying below $2^{\circ} \mathrm{C}$ leave no option but for non-Annex 1 nations to begin significant reductions in emissions as early as 2020-2025, with inevitable repercussions for emissions from their shipping sector [10]. Given this and building on the sovereign nation framing of the shipping sector proposed by the ICS and IMO, non-Annex 1 shipping emissions (under CBDR) are assumed to change at the same rates as those of a mean non-Annex 1 nation (i.e., across the aggregate of all sectors).

\section{Developing mitigation pathways for shipping}

This paper began by transposing high-level statements forthcoming from the international community, in terms of probabilities of preventing $2^{\circ} \mathrm{C}$ of warming, into global emission budgets for the 21 st century. Even with a highly conservative reading of international commitments these budgets place substantial constraints on any subsequent emissions pathway. This section takes these budgets (1321 $\mathrm{GtCO}_{2}$ for $\sim 60 \%$ chance of staying below $2{ }^{\circ} \mathrm{C}$ and $1578 \mathrm{GtCO}$, for a $50 \%$ chance) and develops a small suite of scenarios for shipping, all of which meet the ICS and IMO recommendation that there be a "special global regime for shipping" whereby the sector is assumed to resemble a sovereign nation. Allied with the IMO and ICS's assertion that the shipping sector (as a sovereign nation) will make "at least" its "fair and proportionate contribution" to $2^{\circ} \mathrm{C}$ emission budgets, the analysis proceeds to use updated $\mathrm{CO}_{2}$-only emission pathways from Anderson and Bows as a basis for deriving emission pathways for shipping [10].

If shipping is to be considered a typical nation, it must deliver rates of mitigation "at least as ambitious" as those for the nations with which it is being compared. In this regard, the pathways developed in this paper fall into two regimes. The first (Regime $\mathrm{A}$ ) assumes shipping matches the mitigation effort of a typical global pathway; that is, delivering a rate of mitigation equivalent to the global mean. The second (Regime B) takes account of CBDR and disaggregates global emissions between Annex 1 and non-Annex 1 nations. The mitigation effort required of the respective shipping regions is then assumed to follow the mean rates of change in emissions of either Annex 1 or non-Annex 1 nations. In developing the analysis, this paper makes no judgment as to the veracity or otherwise of arguments on whether or not shipping should be subject to CBDR or, if it is, how Annex 1 and non-Annex 1 shipping should be distinguished (see Gilbert and Bows [24] and Heitmann and Khalilian [25] for assessments of apportionment and allocation of shipping emissions). To ensure the arguments in the discussion section hold for different interpretations of what constitutes Annex 1 and non-Annex 1 shipping, the analysis of Regime B is developed on a proportional rather than absolute basis.

Figure $1 \mathrm{~A}-\mathrm{C}$ illustrates graphically three families of global, Annex 1 and non-Annex 1 emission pathways for cumulative budgets accompanying a 50 and $60 \%$ chance of staying below $2^{\circ} \mathrm{C}$. These budgets are for $\mathrm{CO}_{2}$ only from energy and industry, and assume highly 
(A)

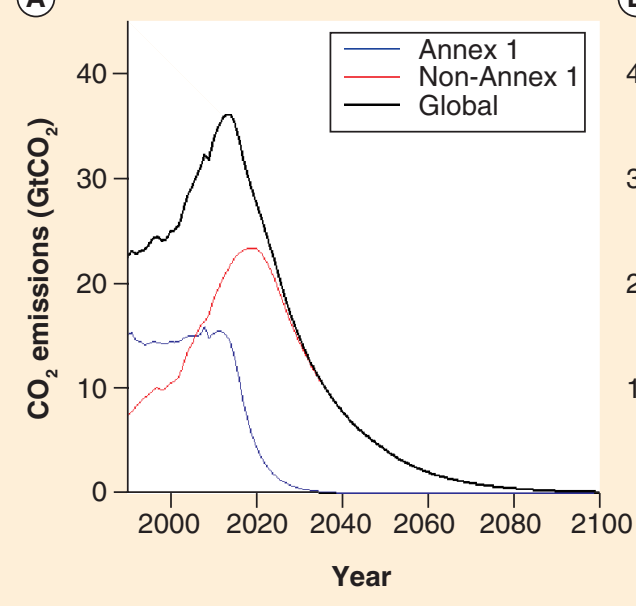

(B)

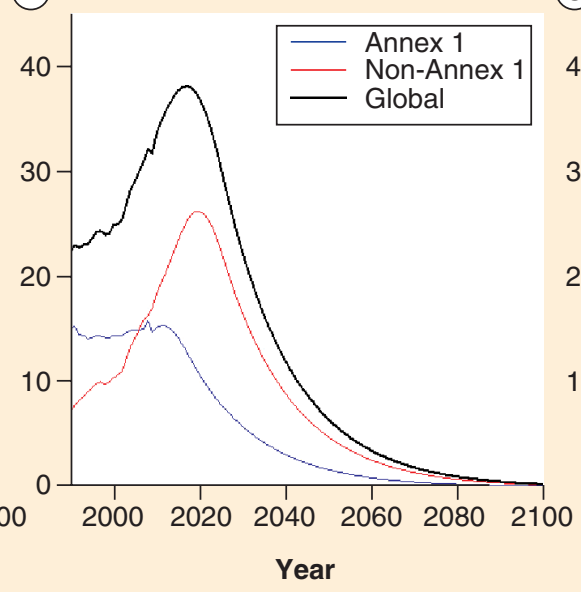

(C)

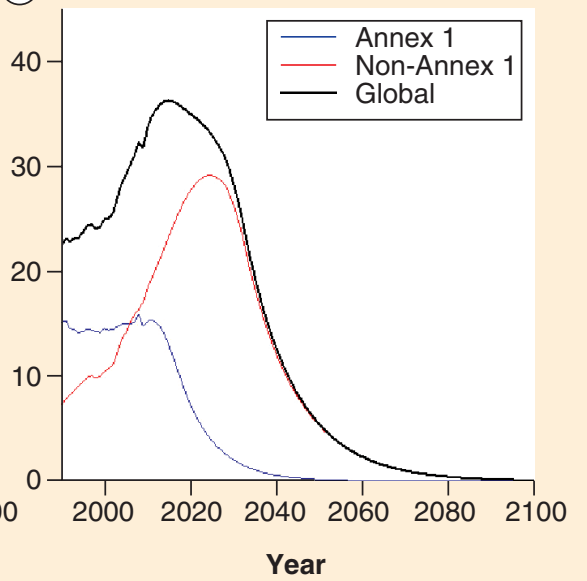

Figure 1. Global, Annex 1 and non-Annex 1 emission pathways of $\mathrm{CO}_{2}$ only from energy with different probabilities of not exceeding $2^{\circ} \mathrm{C}$. (A) Has an approximately $60 \%$ chance; (B) an approximately $50 \%$ chance with a later peak; (C) an approximately $50 \%$ chance with an earlier global (and later non-Annex 1) peak. All pathways are updated versions of those within Anderson and Bows [10].

optimistic reductions in rates of deforestation with the accompanying cumulative emissions $\left(\sim 266 \mathrm{GtCO}_{2}\right.$ between 2000 and 2100) subtracted from total global $\mathrm{CO}_{2}$ emissions [10,26]. The plots are founded on Anderson and Bows' paper [10] adjusted to account for the emission estimates now available for 2009-2010 (5.9\% increase) and 2010-2011 (3.2\% increase) [2]. These values are considerably higher than those Anderson and Bows had assumed in their paper (1.5 and $0.8 \%$, respectively), demonstrating how the already unprecedented high levels of emissions and rapidly eroding $2^{\circ} \mathrm{C}$ emission budgets coupled with relatively small changes in emissions levels can have a disproportionately high impact on the post-peak mitigation rates.

In relation to shipping, the global curves in Figure 1 reflect the rates of mitigation that would be necessary from a shipping industry delivering reductions at least as ambitious as a typical sovereign nation (Regime $\mathrm{A}$ ). The Annex 1 and non-Annex 1 curves similarly illustrate shipping's mitigation effort under a CBDR-based scheme (Regime B). These CBDR pathways build on the Copenhagen Accord's reference to mitigation being developed on the "basis of equity" and "that the time frame for peaking will be longer in developing (nonAnnex 1) countries" [10]. Accordingly, non-Annex 1 emissions are assumed to continue to grow, albeit at a slower rate, out to a peak in emissions in 2020 $\left(40 \%>2^{\circ} \mathrm{C}\right.$ [S1] and $\left.50 \%>2^{\circ} \mathrm{C}[\mathrm{S} 2]\right)$ and $2025(50 \%>$ $\left.2^{\circ} \mathrm{C}[\mathrm{S} 3]\right)$. These dates are chosen to reflect the political, economic and technical constraints of reaching a peak in emissions before 2020 and the impossibility of adhering to the proposed $2^{\circ} \mathrm{C}$ budgets if peaking extends beyond approximately 2025 .
Table 1 quantifies the headline deliverables of the shipping industry if it is to make its fair and proportionate contribution towards global-scale mitigation compatible with 'about as likely as not' chance of $2^{\circ} \mathrm{C}$. It is important to note that all the pathways require an extremely early peak in global emissions. Moreover, even under a CBDR (Regime B) and with Annex 1 nations beginning an immediate transition to rapid annual reductions in emissions, non-Annex 1 nations would still need a peak in shipping emissions by 2025 at the latest.

\section{Comparing $2^{\circ} \mathrm{C}$ pathways with IMO policies}

This section comprises two principal areas of discussion. The first reflects on the IMO's flagship policies, the Energy Efficiency Design Index (EEDI) and the Ship Energy Efficiency Management Plan (SEEMP), comparing their likely impact with the IMO's and ICS's high-level commitments for shipping as a sovereign nation (Regime A). The second builds on this analysis, but with responsibility for the shipping sector's emissions divided between Annex 1 and non-Annex 1 regions, broadly following the UNFCCC framing of CBDR (Regime B).

The analysis in this section is cognizant of discussions ongoing within the IMO as to the potential for 'marketbased mechanisms' to complement (or potentially substitute) forthcoming legislation [27]. However, on reflection, the scope for market-based measures to deliver significant reductions of 'in-sector' emissions appears to be only marginal when compared with the IMO commissioned assessment of reductions from the EEDI and SEEMP [15]. The majority of reductions estimated for the ten market-based measures analyzed by the IMO's 


\begin{tabular}{|c|c|c|c|c|c|c|c|c|c|c|c|c|}
\hline & \multicolumn{3}{|c|}{ Global } & \multicolumn{3}{|c|}{ Annex 1} & \multicolumn{3}{|c|}{ Non-Annex 1} & \multicolumn{3}{|c|}{ Probability of exceeding $2^{\circ} \mathrm{C}(\%)$} \\
\hline & S1 & S2 & S3 & $\mathrm{S} 1_{\mathrm{A}}$ & $\mathrm{S} 2_{\mathrm{A}}$ & $\mathrm{S3}_{\mathrm{A}}$ & $\mathrm{S} 1_{\mathrm{NA}}$ & $\mathrm{S} 2_{\mathrm{NA}}$ & $\mathrm{S}_{\mathrm{NA}}$ & S1 & S2 & S3 \\
\hline $\begin{array}{l}\text { Peak dates } \\
\text { (growth to peak in \%) }\end{array}$ & $\begin{array}{l}2013 \\
(2)\end{array}$ & $\begin{array}{l}2017 \\
(2)\end{array}$ & $\begin{array}{l}2015 \\
(1)\end{array}$ & $\begin{array}{l}2012 \\
(0)\end{array}$ & $\begin{array}{l}2012 \\
(0)\end{array}$ & $\begin{array}{l}2012 \\
(0)\end{array}$ & $\begin{array}{l}2019 \\
(2)\end{array}$ & $\begin{array}{l}2020 \\
(3)\end{array}$ & $\begin{array}{l}2025 \\
(3)\end{array}$ & 40 & 50 & 50 \\
\hline $\begin{array}{l}\text { Years of post-peak } \\
\text { transition (mean \% } \\
\text { reduction rate) }\end{array}$ & $\begin{array}{l}3 \\
(2)\end{array}$ & $\begin{array}{l}6 \\
(2)\end{array}$ & $\begin{array}{l}15 \\
(2)\end{array}$ & $\begin{array}{l}3 \\
(6)\end{array}$ & $\begin{array}{l}5 \\
\text { (3) }\end{array}$ & $\begin{array}{l}6 \\
(8)\end{array}$ & $\begin{array}{l}6 \\
(3)\end{array}$ & $\begin{array}{l}6 \\
(4)\end{array}$ & $\begin{array}{l}8 \\
\text { (4) }\end{array}$ & 40 & 50 & 50 \\
\hline $\begin{array}{l}\text { Post-transition reduction } \\
\text { rate to } 2050(\%)\end{array}$ & 6 & 6 & 8 & 20 & 6 & 12 & 6 & 6 & 8 & 40 & 50 & 50 \\
\hline
\end{tabular}

Expert Group tasked with assessing the "feasibility and impact of possible market-based measures" are achieved "out of sector" [21]. With regards to cumulative emissions accompanying the $2^{\circ} \mathrm{C}$ pathways, the options for trading outside of the sector are so constrained as to have little value (see discussion in the 'Policy and practical implications' section). Consequently, while there is certainly scope for market-based mechanisms to offer marginal in-sector reductions (relatively), they are currently neither sufficiently well developed nor envisaged as capable of delivering significant absolute reductions to be considered here.

\section{- Shipping as a sovereign nation (Regime A)}

The analysis in the previous section took high-level and qualitative statements on climate change by the international community and shipping sector and translated these into quantitative mitigation pathways for the shipping industry. In all but one important respect (i.e., a high probability of $<2^{\circ} \mathrm{C}$ is no longer possible) the translations were literal with declarations of intent taken at face value. The subsequent pathways therefore offer a relatively unambiguous and quantitative representation of the IMO and ICS's headline commitments with respect to the industry's emissions, and against which the detailed mitigation polices of the IMO can be evaluated.

In October 2011, Lloyd's Register in partnership with Det Norske Veritas authored an Assessment of IMO Mandated Energy Efficiency Measures for International Shipping [15]. The IMO commissioned report built on the authoritative Second IMO GHG report (2009), and projected and analyzed the reductions from the EEDI and SEEMP [14]. These flagship mechanisms for controlling shipping emissions were mandated by the Marine Environment Protection Committee in July 2011. Both the EEDI and SEEMP come into force from the start of 2013 and will apply to all new ships of 400 gross tonnes and above.

The Assessment of IMO Mandated Energy Efficiency Measures for International Shipping is a detailed report in which a range of scenarios are developed of the industry's emissions out to 2050. The IMO's fleet growth assumptions are based on two of the Special Report on Emissions Scenarios (SRES) families, A1B and B2 (the earlier second IMO GHG report used the full range of SRES scenarios, the majority of which fit within the A1B to $\mathrm{B} 2$ range) [28]. The $\mathrm{A} 1 \mathrm{~B}$ scenario is one of the higher growth scenarios of the SRES range (A1FI is higher in the longer term) and is broadly reflective of recent trends. B2 is still a growth scenario, but assumes notably lower economic growth and consequently a lower rate of fleet expansion.

The IMO emission scenarios are developed assuming different levels of uptake (waivers) of the EEDI and SEEMP. However, for this analysis the high-level mitigation pathways (S1, S2 and S3) developed in the previous section are compared with full implementation of both the EEDI and SEEMP mechanisms. It is this optimistic interpretation of emissions reductions forthcoming from the EEDI and SEEMP that is compared, in Figure 2B, with the IMO's and ICS's highlevel assurances of what the shipping industry will deliver on climate change.

Figure 2 graphically illustrates the gulf between what is a generous interpretation of the IMO and ICS oftstated assurances on climate change and the impending failure of their much-heralded policies to reconcile shipping emissions with these assurances. It is difficult to exaggerate the scale of divergence between what is evidently high-level rhetoric around the industry's mitigation efforts and the theoretical potential of the IMO's principal policy instruments. Table 2 quantifies the key differences, contrasting shipping's fair and proportionate contribution to a $2^{\circ} \mathrm{C}$ future with the industry's emission projections out to 2050 .

If global economic growth continues at rates a little below recent historical trends (A1B), and the IMO's flagship emission reduction measures are implemented in full, shipping emissions are set to rise (c.f. 1990) by approximately $300 \%$ by 2050 (i.e., a fourfold increase). Even compared with 2010, the IMO report suggests a rise in emissions of nearly $200 \%$ by 2050 . However, as Figure 2 reveals, growth in shipping and in shipping emissions is typically higher than growth in 
(A)

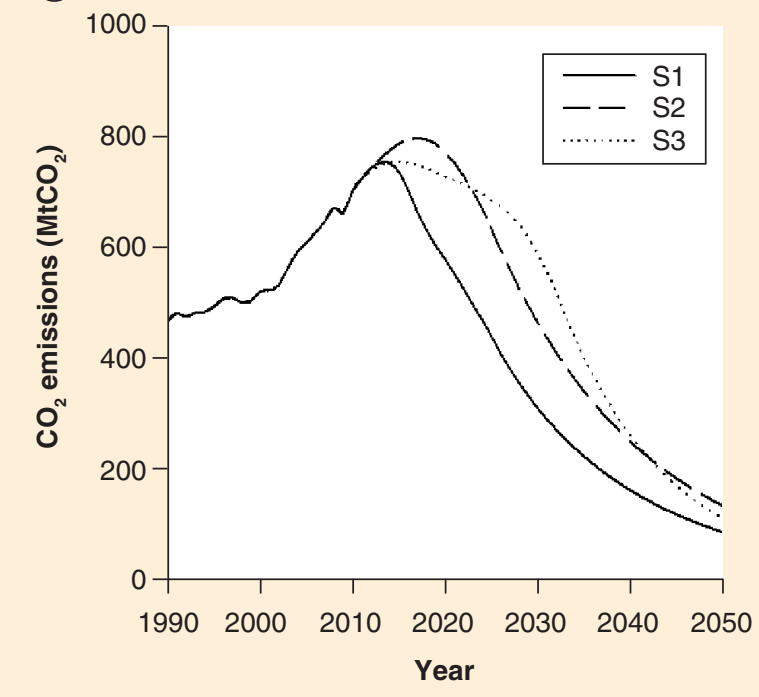

(B)

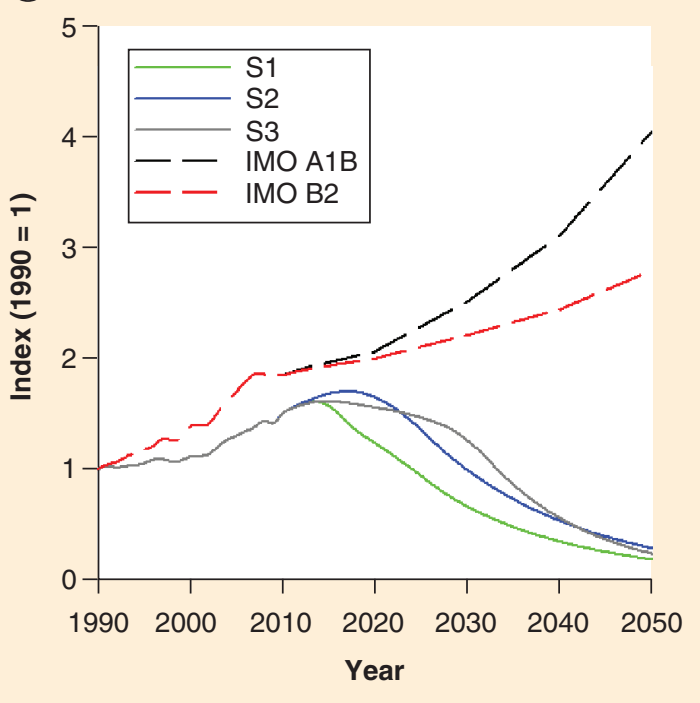

Figure 2. Comparison of $2^{\circ} \mathrm{C}$ and International Maritime Organization mitigation pathways. (A) Global $2^{\circ} \mathrm{C}$ mitigation pathways from Figure 1 translated into global shipping emissions using a 1990 baseline. (B) Comparison of the two mitigation scenarios for shipping (related to A1B and B2) taken from the IMO report of 2011 with the emission pathways $\mathrm{S} 1, \mathrm{~S} 2$ and $\mathrm{S} 3$ commensurate with $2^{\circ} \mathrm{C}$ implied if shipping is treated as a sovereign nation (all indexed to 1990) [15].

IMO: International Maritime Organization; S1: $40 \%>2^{\circ} \mathrm{C}$ in 2020; S2: 50\% > $2^{\circ} \mathrm{C}$ in 2020; S3: 50\% > $2^{\circ} \mathrm{C}$ in 2050.

gross domestic product (see period 1990-2010) and, consequently, the IMO scenarios could reasonably be described as reflecting the more optimistic end of the orthodox spectrum of emission estimates.

The divergence between the IMO and ICS headline rhetoric on mitigation and the quantified assessment of their policies is starker still than the $300 \%$ rise suggests. If the sovereign nation of shipping is to deliver at least its fair and proportionate contribution to a likely as not chance of $2^{\circ} \mathrm{C}$, its emissions need to reduce by approximately $70-80 \%$ from their 1990 levels by 2050 (this assumes shipping follows a stringent emissions pathway similar to that outlined in Figure 1). Bringing this forward to $2010\left(866 \mathrm{MtCO}_{2}\right)$, a reduction of $85-90 \%$ is necessary, with emissions falling to between 87 and $135 \mathrm{MtCO}_{2}$ by 2050.

Relating these 2050 figures, derived from the IMO and ICS's headline statements, to those proposed under the IMO's A1B future, show the discrepancy rising an order of magnitude to between 1400 and $2200 \%$. Even if the economic constraints of $\mathrm{B} 2$ are assumed to dominate the coming decades, the difference between

Table 2. Summary of shipping scenarios A1B and B2 in terms of emissions and changes relative to 1990 and 2000.

\begin{tabular}{|c|c|c|c|c|}
\hline \multirow[t]{2}{*}{ Year } & \multicolumn{2}{|c|}{ IMO's high emission scenario family (A1B) } & \multicolumn{2}{|c|}{ IMO's low emission scenario family (B2) } \\
\hline & $\begin{array}{l}\text { Total shipping } \\
\text { emissions }\left(\mathrm{MtCO}_{2}\right)\end{array}$ & $\begin{array}{l}\text { \% increase relative to } \\
\text { shipping emissions in } \\
1990 \text { (and 2000) }\end{array}$ & $\begin{array}{l}\text { Total shipping } \\
\text { emissions }\left(\mathrm{MtCO}_{2}\right)\end{array}$ & $\begin{array}{l}\text { \% increase relative to } \\
\text { shipping emissions in } \\
1990 \text { (and 2000) }\end{array}$ \\
\hline 1990 & 468 & & 468 & \\
\hline 2000 & 647 & $38(0)$ & 647 & $38(0)$ \\
\hline 2010 & 866 & $85(34)$ & 866 & $85(34)$ \\
\hline 2013 & 901 & $93(39)$ & 892 & $91(38)$ \\
\hline 2020 & 965 & $106(49)$ & 936 & $100(45)$ \\
\hline 2030 & 1176 & $151(82)$ & 1034 & $121(60)$ \\
\hline 2040 & 1454 & $125(1143)$ & 1143 & $144(77)$ \\
\hline 2050 & 1895 & 305 (193) & 1308 & 179 (102) \\
\hline
\end{tabular}


the IMO's high-level rhetoric and policy reality remains high at $950-1500 \%$.

These 2050 numbers are all premised on shipping emissions remaining within a tightly constrained 21st-century carbon budget. However, as is evident from Figure 2, the shipping sector is already above and rapidly diverging from any reasonable $2^{\circ} \mathrm{C}$ emissions pathway. Consequently, if shipping is not to exceed its carbon budget, developed in accordance with the ICS's insistence that the sector's contribution "must be proportionate to shipping's share of the total global emissions (less than 3\%)," the 2050 emissions will likely have to be below $87-135 \mathrm{MtCO}_{2}$ to compensate for its current emission trajectory. This suggests a yet further increase in the percentage discrepancy noted earlier.

The scale of divergence between the industry's claims to be reducing its emissions and the rapid emissions growth enshrined within the IMO's detailed scenarios is stark; so much so that this analysis risks being dismissed simply as a mistake or a misunderstanding of the numbers. To help alleviate such concern, the following bullet points summarize the fundamental reasoning behind the analysis, demonstrating succinctly how such a level of divergence has arisen:

- The shipping sector expressly wants to be exempt from 'national $\mathrm{CO}_{2}$ reductions targets', instead being subject to a "special global regime for shipping" with the sector ostensibly treated as if it were a sovereign nation;

- The IMO and ICS assert it will deliver on mitigation "at least as ambitious" as the "global community pursue" under the Copenhagen Accord and Cancun Agreements (i.e., to hold below $2^{\circ} \mathrm{C}$ );

- Even a highly conservative reading of the science and accompanying probabilities suggests that an approximately $50: 50$ chance of avoiding $2^{\circ} \mathrm{C}$ demands a $70-80 \%$ (compared with 1990) reduction in emissions from energy by 2050 (assuming a stringent emissions pathway is followed);

- Contrasting these high-level objectives with the detailed analysis of the IMO demonstrates that its flagship mitigation mechanisms (EEDI and SEEMP) are set to deliver a rise in emissions from $468 \mathrm{MtCO}_{2}$ in 1990 to $1895 \mathrm{MtCO}_{2}$ in 2050; an increase of approximately $300 \%$ rather than a reduction of approximately $80 \%$ (to $\sim 100 \mathrm{MtCO}_{2}$ );

- Set against the IMO, ICS and global communities' commitment to "hold the increase in global temperature below $2^{\circ} \mathrm{C}$ ", the shipping industry's EEDI and SEEMP leave the sector on a trajectory for emissions to be approximately 2200\% higher by 2050 than is their fair and proportionate contribution.
Further to concerns over the gulf between the industry's high-level declarations and mandated policies on mitigation is a serious unease with regards to the language typically used to describe the predicted and unprecedented increase in absolute emissions.

The IMO's 2011 report repeatedly refers to how "mandatory reduction measures [EEDI and SEEMP] from 2013 and onwards will lead to significant emission reductions by the shipping industry"; this is despite the quantitative analysis showing a two- to four-fold increase in $\mathrm{CO}_{2}$ emissions (compared with 1990) [15].

Within the 61-page report, the reduction in shipping $\mathrm{CO}_{2}$ emissions is referred to on 53 pages, with the word 'reduction' used in excess of 300 occasions to describe the industry's rapidly rising emissions. In contrast, the report makes brief reference on just four occasions to how "none of the scenarios will achieve a reduction in absolute total $\mathrm{CO}_{2}$ level from shipping relative to year 2010" [15].

\section{- Shipping under CBDR (Regime B)}

The analysis demonstrates how any reasonable interpretation of the IMO and ICS's high-level proposals for international shipping implies radical and early emissions reductions. However, while the overall global cap may be severely constrained, moving from the IMO's principle of "no more favorable treatment" towards a differential division of mitigation, does offer some latitude for non-Annex 1 regions, but at the expense of still more stringent caps for Annex 1 .

Figure $3 \mathrm{~A}-\mathrm{C}$ recast the pathways demonstrated earlier in Figure 1A-C into shipping-specific levels of mitigation relative to 1990 . Figure 3 A presents shipping as a single sovereign nation, similar to the plots in Figure $2 \mathrm{~A}$ (Regime A), but illustrating percentage change rather the absolute emissions. Figure 3B \& C illustrates global emissions apportioned in accordance with Regime B (based on CBDR), with the three plots configuring the curves from Figure $1 \mathrm{~A}-\mathrm{C}$ in terms of percentage change relative to 1990 .

While Figure $3 \mathrm{~A}$ illustrates graphically the IMO and ICS's preference for a regime based on 'no more favorable treatment', it fails to address the Copenhagen Accord's emphasis on equity, specifically "that the time frame for peaking will be longer in developing (non-Annex 1) countries." In this regard, Figure 3B \& C more appropriately captures the equity dimension of international agreements. The growth in emissions, from non-Annex 1 shipping out to a peak between 2020 and 2025 , is compensated by a much more challenging reduction rate in emissions from Annex 1 shipping. However, despite weighting the global $2^{\circ} \mathrm{C}$ emission budgets in favor of the non-Annex region, the pathways in Figure 3B are nevertheless very challenging for those 


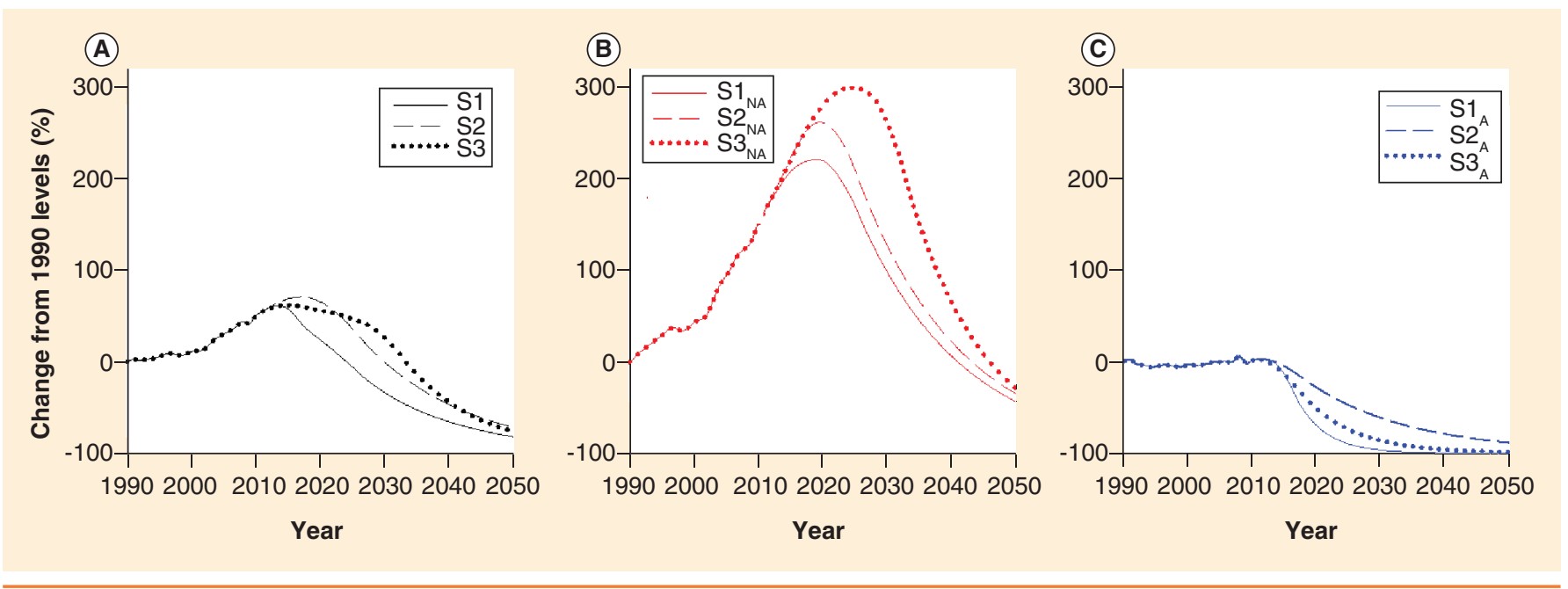

Figure $3.2^{\circ} \mathrm{C}$ emission pathways for shipping. (A) Global shipping emissions pathways to avoid $2^{\circ} \mathrm{C}$ assuming global shipping is treated as a sovereign state (Regime A). (B) Non-Annex 1 shipping emissions pathways for a $40-50 \%$ chance of exceeding $2^{\circ} \mathrm{C}$ assuming global shipping's emissions follow the same pathway as non-Annex 1 emissions (Regime B). (C) Annex 1 shipping emissions pathways for a $40-50 \%$ chance of exceeding $2^{\circ} \mathrm{C}$ assuming global shipping's emissions follow the same pathway as Annex 1 emissions (Regime B). A: Annex 1; NA: Non-Annex 1; S1: $40 \%>2^{\circ} \mathrm{C}$ in 2020; S2: 50\% > $2^{\circ} \mathrm{C}$ in 2020; S3: 50\% > $2^{\circ} \mathrm{C}$ in 2050.

nations. Not only are 2020 and even 2025 very early peaks, but the emission growth rate to those peaks is substantially lower than the trend in economic growth for the non-Annex 1 region; historically, growth in shipping (and hence emissions) typically exceeds economic growth. Moreover, the post-peak emission reduction soon reaches between 6 and $8 \%$ per annum. Consequently, even a CBDR-based apportionment of shipping's contribution to $2^{\circ} \mathrm{C}$ places substantial and early constraints on shipping associated with non-Annex 1 nations.

Turning to the small remaining emission space for Annex 1 nations, the challenge is clear and the policy implications are without precedent. Annex 1 shipping needs to begin reducing its absolute emissions immediately, rapidly moving through a period of transition and towards absolute mitigation rates of $6-12 \%$ per annum (Table 1). The prospect of such austere reductions may prompt comment that shipping emissions are too skewed in favor of the non-Annex 1 nations. However, it is worth noting that if, in 1990, the division of shipping emissions between Annex 1 and non-Annex 1 mirrored those of energy-related emissions, the cumulative split of shipping's 2000-2050 emission budget would be approximately 30 and $70 \%$, respectively. Developing this further, and assuming UN's median population projection, the per-capita (calculated for 2000-2050) apportionment between Annex 1 and non-Annex 1 would essentially reverse to approximately 70 and $30 \%$.

Ultimately, the real challenge for the shipping industry arises not from how to divide shipping's emissions between non-Annex 1 and Annex 1, but from the small and rapidly reducing carbon budget accompanying the international community's $2^{\circ} \mathrm{C}$ commitment. The unprecedented scale of mitigation demanded of shipping in this paper is commensurate with the ICS's contention that the industry's contribution should be proportionate to its role in global emissions $(<3 \%)$. Each of the three global shipping pathways (S1, S2 and S3) describe 2000-2050 carbon budgets equivalent to a little over $2 \%$ of the total global energy-only budget. Similarly, each pair of non-Annex 1 and Annex 1 pathways $\left(S 1_{\mathrm{A}}, S 1_{\mathrm{NA}}\right.$ and so on) collectively meets the ICS criteria of representing under $3 \%$ of the global carbon budget.

\section{Policy \& practical implications}

This paper compares high-level and quantitative statements on climate change from both the international community and representative bodies of the shipping industry, with the key mitigation policies mandated for that industry. Although the analysis is independent of political or industrial sensibilities, where a range of quantitative values or probabilities reflects qualitative statements, the paper favors the more conservative position. Consequently, while the conclusions may point to a fundamental rethink of the role of shipping in contemporary society, they are premised on a dispassionate and orthodox analysis.

The IMO and ICS's assertion that the sovereign nation of shipping should deliver mitigation in line with global community's commitment to $2^{\circ} \mathrm{C}$ is in complete contradiction to the measures it proposes. 
This paper demonstrates that a shipping industry not in receipt of favorable treatment would need to rapidly transit to a low-carbon pathway, delivering in the region of an approximately $80 \%$ reduction in absolute emissions by 2050. By contrast, and even with full implementation of the industry's flagship mitigation measures, shipping emissions are set to increase fourfold compared with 1990. The scale of the void between what is necessary and what is proposed is staggering; this would remain the case even if proposed marketbased mechanisms were to be agreed and implemented [27]. Assuming economic growth a little below recent trends, the industry envisages shipping emissions in 2050 of $1895 \mathrm{MtCO}_{2}$; this contrasts with shipping's fair and proportionate contribution to a 50:50 chance of holding the increase in global temperature below $2^{\circ} \mathrm{C}$ of approximately $100 \mathrm{MtCO}_{2}$. In short, even if the industry's EEDI and SEEMP are fully implemented, shipping emissions in 2050 will be almost 2000\% higher than the IMO and ICS's rhetoric suggests.

Turning to cumulative emissions, the ICS and IMO repeatedly emphasize that the industry's mitigation efforts "must be proportionate to shipping's share of the total global emissions (less than 3\%)." However, while the three $2^{\circ} \mathrm{C}$ pathways developed in this paper (S1, S2 and S3) deliver on the 3\% criteria, the IMO's own pathways represent in the region of $8 \%$ of the total cumulative budget for $2^{\circ} \mathrm{C}$.

Against such a backdrop of quantitative confusion, this article suggests the previous IMO SecretaryGeneral's assertion that "it is always important to proceed with due diligence and make decisions only after the debate, on the basis of well-founded argumentation" masks a much more opportunist reality [29]. This challenging statement is further supported through examining the language used by the IMO and ICS in describing how shipping emissions are anticipated to develop over the coming decades. While the quantitative detail within all the major IMO climate change reports confirms rapidly rising emissions, the qualitative language, with few exceptions, describes reductions in emissions. The smoke and mirrors in all this is provided by business-as-usual scenarios, against which reductions are projected to occur. For example, while the IMO's 2011 report projects a quantitative rise in absolute emissions of $1427 \mathrm{MtCO}_{2}$ (compared with 1990) by 2050 (for an A1B future), the more generic description of this is of a $41.1 \%$ emission reduction (compared with 2010) [15]. As noted earlier, it is this language of 'reductions' that dominates the qualitative narrative of the 2011 and other IMO reports on emissions. Similarly, the language of 'reduction' is regularly evoked by the ICS. When their chairman asserts, "shipping ... should play its part in reducing
$\mathrm{CO}_{2}$ emissions" noting the IMO's "ground breaking agreement on technical and operational measures to reduce shipping's $\mathrm{CO}_{2}$ ", it is not evident that the reduction he refers to is, according to the industry's own analysis, actually a fourfold increase in emissions.

In an idealized world, the divergence between the shipping industry's reality and rhetoric could, at least to a degree, be alleviated through carbon trading or the imposition of significant and additional carbon-related costs. However, in practice, trading is not viable as the abject failure of the shipping industry to mitigate its emissions in line with $2^{\circ} \mathrm{C}$ is paralleled by other sectors' and nations' similar failure. Consequently, meaningful $2^{\circ} \mathrm{C}$ trading, premised on the scientific framing of cumulative budgets rather than inappropriate longterm targets, would be dominated by buyers, both nations and industries. The dilemma described in this paper is therefore not only of consequence to the shipping industry, but has repercussions across all nations and, less directly, industries.

Nonetheless, shipping, as the IMO and ICS imply, is arguably more culpable than are other industries. As they repeatedly stress, the unique nature of shipping demands a dedicated and "special global regime" with it "treated like a sovereign state in its own right". Therefore, while industries are typically subject to the authority and control of their respective nation states, shipping, under the auspices of the IMO, has direct responsibility for its own emissions. Accordingly, if it is to claim scientific legitimacy and coherence for its stated position on climate change, it is incumbent solely on the IMO to reconcile shipping's high-level commitments with its detailed policies. In this regard, shipping is unique amongst industries. As such, the IMO needs to either rapidly implement measures for reducing its absolute emissions or openly renege on its high-level commitments; that is, to reject international obligations approximately $2^{\circ} \mathrm{C}$ and prevention of 'dangerous interference with the climate system'.

This penultimate section assumes the IMO are to maintain their stated commitments and deliver shipping mitigation "at least as ambitious" as the "global community2 have approved through the Copenhagen Accord and Cancun Agreement. The question thus arises, what are the implications for shipping of transitioning from a planned $2000 \%$ rise in emissions to an $80 \%$ reduction (compared with 1990 ) by 2050 , all set within a $75 \%$ smaller carbon budget?

\section{- Reconciling shipping emissions with a conservative interpretation of $2^{\circ} \mathrm{C}$}

The intention of the following suggestions is not to provide a definitive priority of action, but rather 
to give a flavor of what the scale and immediacy of emission reduction outlined in this paper demand of the industry. While in isolation the suggestions may be denounced as naive and misguided, it is important they be set within the context of the IEA's assessment that existing emission trends are in line with a $6^{\circ} \mathrm{C}$ rise by 2100 [5]. Moreover, as the then Secretary-General of the IMO noted in 2009, "whether we like it or not, our collective way of life has become unsustainable... This cannot, and should not, go on. We need to make some tough decisions, we need to make them now" [6]. Popular or not, the proposals outlined here are in keeping with these IEA and IMO statements and, most importantly, are founded on a scientifically literate view of climate change as a cumulative, and not an endpoint, issue.

To understand the quantitative levels of mitigation shipping needs to deliver, Table 3 summarizes the decadal reductions accompanying a fair and proportionate contribution to an approximate 50:50 chance of $2^{\circ} \mathrm{C}$ stabilization.

\section{- Illustrative proposals for delivering a decarbonized shipping industry}

The following provisional suggestions are intended to complement those more incremental improvements in relative operational and technical efficiency captured in the EEDI and SEEMP.

\section{Changes within $1-10$ years}

These are likely to be driven principally within existing ships and infrastructure:

- Slow steaming for all but exceptional loads;

- Optimized logistics for minimum fuel use with fleetwide implementation prioritized over commercial merit;

- Immediate and mandatory fuel consumption reporting;

- Shifts in demand and goods freighted (guarding against substitution to higher-carbon freight modes);
- A comprehensive programme of low-carbon retrofit (including renewable energy supplements; e.g., kites);

- A significant increase in the scrappage rate beyond the 3\% typically considered [15].

These measures, complemented with the SEEMP and EEDI, would need to be ratcheted up to a level where they collectively deliver in the region of a $15 \%$ reduction in absolute emissions by around 2020 . Provisional analysis suggests this is viable (i.e., $~ 2 \%$ improvement in fleet efficiency per annum), but it would be highly unlikely that in the short term even such a modest absolute reduction could be reconciled with significant growth in global freight.

\section{Changes between 2020 \& 2030}

Alongside a continuation in the rapid roll-out of incremental improvements identified above, the following more fundamental changes would need to be penetrating the industry:

- High-efficiency, low-carbon ships designed for slow steaming and highly optimized logistics (prompted by increased scrappage rates);

- New commercial models commensurate with fleetwide, low-carbon optimization (collaboration co-existing with competition) widespread amongst major ship operators;

- Low-carbon fuels throughout existing fleet and above levels in EEDI and SSEMP, including sustainably certified biofuels;

- Significant increase in freight tariffs changing demand and forcing shifts in customer practices;

- Rapid reduction in fossil fuel trade driven by an expansion of decarbonized and indigenous renewable energy [30].

The technical, operational and economic transitions outlined here have the potential to catalyze further low-carbon changes both within the freight industry and across the customer base. Nevertheless, the 3.5\%

\section{Table 3. Decadal reduction in emissions from shipping for an approximately $50: 50$ chance of $2^{\circ} \mathrm{C}$.}

\begin{tabular}{|c|c|c|c|}
\hline Year & $\begin{array}{l}\text { Change } \\
\text { (compared with 1990) }^{\dagger}\end{array}$ & $\begin{array}{l}\text { Change } \\
\text { (compared with 2010) }^{\ddagger}\end{array}$ & $\begin{array}{l}\text { Actual emissions } \\
\left(\mathrm{MtCO}_{2}\right)^{\S}\end{array}$ \\
\hline 2020 & $\sim 60 \%$ increase & $\sim 15 \%$ reduction & $\sim 750$ \\
\hline 2030 & $\sim 15 \%$ increase & $\sim 40 \%$ reduction & $\sim 530$ \\
\hline 2040 & $\sim 45 \%$ reduction & $\sim 70 \%$ reduction & $\sim 260$ \\
\hline 2050 & $\sim 75 \%$ reduction & $\sim 85 \%$ reduction & $\sim 120$ \\
\hline
\end{tabular}


per annum reductions in absolute emissions necessary to deliver the 2030 target will still place substantive constraints on any growth of the sector.

\section{Changes between 2030 \& 2050}

This is the period where the previous groundwork needs to initiate an annual emission reduction rate almost twice that of the previous decade. This requires not only continued vigilance on maintaining and, where possible, increasing the incremental changes already set in train, but also demands a wholesale shift to very low-carbon vessels allied with potentially controversial reductions in demand, for example:

- Very stringent regulation or incentive mechanisms to deliver a wholesale shift to low-carbon shipping;

- Highly optimized and coordinated merchant fleet providing very low-carbon trade - with costs passed onto the customers;

- High scrappage rate moderated through more modular design;

- Where technical and operational efficiencies are unable to deliver on obligatory reductions, demand management becomes unavoidable.

Post-2030, the emission reduction rate is over $6 \%$ per annum - with an almost decarbonized merchant fleet operating internationally by 2050 . The threat of demand management has the potential to prompt a near-paradigm shift in the industry, with many practices previously considered unworkable now having a niche in a reformed industrial structure. Overall, however, the obligation to reduce emissions by $85 \%$ compared with $2010 / 2012$ is liable to take its toll on the total tonnage of goods traded. This may, to a degree, be compensated by a substantial rise in the value per tonne of goods transported.

\section{Conclusion}

In 2012, with GHG emissions rising at unprecedented rates to unprecedented levels, one clear certainty is that the future will be very different from the past. Whether this future manages the excesses of the present within planetary boundaries, or whether, as the IEA chief economist notes, we continue towards "a temperature increase of $6^{\circ} \mathrm{C}$ ” with "devastating consequences for the planet", is a decision the international community now faces.

As it stands, the shipping industry's response extends across the 'horns of the dilemma'. On the one hand the IMO and ICS maintain a strong but rhetorical pretence of making their fair and proportionate contribution towards global commitments on climate change, while on the other, they simultaneously are planning for emissions to rise by almost 300\% compared with those from the industry in 1990.

The shipping sector's high-level declarations of responsible action contrasting with woefully inadequate policies are reflective of the Machiavellian duality exhibited by many industries and nations. This paper, with its focus on shipping, has sought to clarify the scale of the apparent masking of rapid, substantial and planned emissions growth by the industry. The paper concludes that for shipping to make its "fair and proportional" contribution to even an outside chance of "preventing dangerous interference with the climate system" a fundamental change in its emissions pathway is essential.

The final words of this article are appropriately those of the then Secretary-General of the IMO and his succinct and candid observations on our present malaise with regards to mitigation: "This cannot, and should not, go on. We need to make some tough decisions, we need to make them now ... Faced with facts we cannot argue against, we need to consider our priorities and accept that we have to make certain sacrifices; we need to start putting 'life' ahead of 'lifestyle.'”

\section{Future perspective}

As we accelerate towards dangerous levels of climate change it is difficult not to be pessimistic about the future. At the same time as there is a growing void between modeled pathways for $2^{\circ} \mathrm{C}$ and trends in fossil fuel emissions, others are couching increases in absolute emissions as reductions. As long as this misleading situation continues, those with the power to deliver change will remain ill-equipped to develop appropriate mitigation and adaptation strategies. By contrast, if academics communicate plainly the stark implications of failing to address short-term mitigation, sectors such as international shipping would be required to recast their polices away from incremental and towards step-change responses to climate change. Communication and debate is key, and it is the responsibility of academics to engage candidly and robustly with industry, policymakers and civil society.

\section{Acknowledgements}

The authors thank P Gilbert, S Mander, A Sidhu, M Traut and $C$ Walsh for their comments and support.

Financial \& competing interests disclosure

The authors are grateful to the UK Engineering and Physical Sciences Research Council Energy Programme for funding the High Seas Project. The authors have no other relevant affiliations or financial involvement with any organization or entity with a financial interest in or financial conflict with the subject matter or materials discussed in the manuscript apart from those disclosed. No writing assistance was utilized in the production of this manuscript. 
The global context

- Growth in global fossil fuel emissions across all sectors is significant and escalating.

- Mitigation efforts of all sectors, including international aviation and shipping, are coming under increasing scrutiny.

Shipping's headline commitments on climate change

- Both the International Maritime Organization (IMO) and the International Chamber of Shipping (ICS) are adamant that the "shipping industry is committed to playing its part in further reducing its $\mathrm{CO}_{2}$ emissions" and that it "must be proportionate to shipping's share of the total global emissions (less than 3\%)."

- The ICS go further and suggest the industry's $\mathrm{CO}_{2}$ emission reductions "should be at least as ambitious as the $\mathrm{CO}_{2}$ emissions reduction agreed under any new UN Climate Change Convention."

Quantifying mitigation objectives for shipping

- This analysis adopts a literal translation of high level statements from the shipping sector with regard to climate change mitigation commitments.

- The language of climate change obligations is translated into a quantitative framing of absolute reductions in emissions, along with accompanying rates of mitigation.

Developing mitigation pathways for shipping

- Using $2^{\circ} \mathrm{C}$ cumulative budgets from Anderson and Bows, a suite of emissions pathways for shipping, in line with the ICS and IMO recommendation that there be a "special global regime for shipping", are developed.

- Complementing these, a suite of similar pathways reflecting how "common but differentiated responsibility" may play out for shipping are also illustrated, with a simple split between Annex 1 and non-Annex 1 nations.

Comparing $2^{\circ} \mathrm{C}$ pathways with IMO policies

- The pathways are compared with IMO scenarios that include mitigation measures enshrined in the Energy Efficiency Design Index and Ship Energy Efficiency Management Plan.

- Results show that an approximately 50:50 chance of avoiding $2^{\circ} \mathrm{C}$ demands a $70-80 \%$ (c.f. 1990) reduction in shipping emissions by 2050 , with shipping treated "as a sovereign state".

- The IMO's flagship mitigation mechanisms (Energy Efficiency Design Index and Ship Energy Efficiency Management Plan) are set to deliver a rise in emissions from $468 \mathrm{MtCO}_{2}$ in 1990 to $1895 \mathrm{MtCO}_{2}$ in 2050 - an increase of approximately $300 \%$.

- Even with "common but differentiated responsibility", non-Annex 1 shipping emissions must soon peak and reduce at 6-8\% per annum thereafter; Annex 1 shipping requires an immediate reduction in emissions of 12\% per annum (Table 1).

Policy \& practical implications

- Ultimately, the real challenge for the shipping industry arises not from how to divide shipping's emissions between non-Annex 1 and Annex 1, but from the small and rapidly reducing carbon budget accompanying the international community's $2^{\circ} \mathrm{C}$ commitment.

- For shipping to make its 'fair and proportional' contribution to even an outside chance of avoiding a $2^{\circ} \mathrm{C}$ temperature rise, a fundamental change in its emissions pathway is essential.

\section{References}

Papers of special note have been highlighted as:

- of interest

- of considerable interest

1 Commercial Fishing Industry Vessel Safety Advisory Committee. Man Overboard Prevention and Recovery: Best Practices. US Coast Guard, Washington, DC, USA (2010).

2 International Energy Agency. Global Carbon-Dioxide Emissions Increase by $1.0 \mathrm{Gt}$ in 2011 to Record High. International Energy Agency, Paris, France (2012).

3 UN. United Nations Framework Convention on Climate Change. UN, NY, USA (1992).

4 International Energy Agency. World Energy Outlook. International Energy Agency, Paris, France (2011).

5 Rose M. UPDATE 2 - Global $\mathrm{CO}_{2}$ Emissions Hit Record in 2011 Led by China-IEA.

Reuters, NY, USA (2012).
- Recognition by a respected energy body that the current emission trajectory is incompatible with $2^{\circ} \mathrm{C}$ futures, and more closely aligned to $6^{\circ} \mathrm{C}$ of warming.

6 International Maritime Organization. IMO NEWS. International Maritime Organization, London, UK (2009).

- An impassioned message marking World Maritime Day (2009) offered an uncompromising assessment of the challenges facing the global community.

7 UNFCCC. Copenhagen Accord. UN, Geneva, Switzerland (2009).

8 EC. Limiting Global Climate Change to 2 Degrees Celsius: The Way Ahead for 2020 and Beyond. EU, Brussels, Belgium (2007).

9 Department of Energy and Climate Change. The UK Low Carbon Transition Plan:
National Strategy for Climate and Energy. Department of Energy and Climate Change, London, UK (2009).

10 Anderson K, Bows A. Beyond 'dangerous' climate change: emission scenarios for a new world. Philos. Transact. A Math. Phys. Eng. Sci. 369(1934), 20-44 (2011).

- Highlights the importance and implications of continued growth in the short term of non-Annex 1 nation emissions for a range of probabilities of avoiding $2^{\circ} \mathrm{C}$. It is used to underpin the shipping emission pathway development in this paper.

11 Allen MR, Frame DJ, Huntingford C et al. Warming caused by cumulative carbon emissions towards the trillionth tonne. Nature 458(7242), 1163-1166 (2009).

12 Mastrandrea MD, Field CB, Stocker TF et al. Guidance Note for Lead Authors of the IPCC Fifth Assessment Report on Consistent Treatment 
of Uncertainties. IPCC, Geneva, Switzerland (2010).

13 Macintosh A. Keeping warming within the $2{ }^{\circ} \mathrm{C}$ limit after Copenhagen. Energy Policy 38(6), 2964-2975 (2010).

14 Buhaug O, Corbett JJ, Endresen O et al. Second IMO GHG Study 2009. International Maritime Organization, London, UK (2009).

- Comprehensive analysis of mitigation in the shipping industry, where emission scenarios projecting future shipping $\mathrm{CO}_{2}$ are included.

15 Bazari Z, Longva T. Assessment of IMO Mandated Energy Efficiency Measures for International Shipping: Estimated $\mathrm{CO}_{2}$ Emissions Reduction from Introduction of Mandatory Technical and Operational Energy Efficiency Measures for Ships. International Maritime Organization, London, UK (2011).

16 International Maritime Organization. Control of Greenhouse Gas Emissions from Ships Engaged in the International Trade. UN, Geneva, Switzerland (2009).

17 Mitropoulos E. Dinner speech. Presented at: Seoul International Maritime Forum. Seoul, South Korea, 14 October 2010.

18 International Chamber of Shipping. Key Issues - The Year in Review. International Chamber of Shipping, London, UK (2012).

19 Polemis SM. Balancing Environmental Aspirations with Economic Realities. International Chamber of Shipping, London, UK (2012).

20 The Chamber of Shipping. A Global Cap-and-Trade System to Reduce Carbon Emissions from International Shipping. The Chamber of Shipping, London, UK (2009).
21 Marine Environment Protection Committee. Reduction of GHG Emissions From Ships. International Maritime Organization, London, UK (2010).

22 International Maritime Organization. Position Statement on the Control of Greenhouse Gas Emissions From Ships at Ad-Hoc Working Group on Long-Term Cooperative Action. UN, Geneva, Switzerland (2011).

23 International Chamber of Shipping. Shipping, World Trade and $\mathrm{CO}_{2}$ Emissions. UNFCCC, Bonn, Germany (2011).

24 Gilbert P, Bows A. Exploring the scope for complementary sub-global policy to mitigate $\mathrm{CO}_{2}$ from shipping. Energy Policy 50 , 613-622 (2012).

- Highlights the difficulties with apportioning shipping emissions to nations, and provides discussion of recent policy developments towards mitigation across the sector.

25 Heitmann N, Khalilian S. Accounting for carbon dioxide emissions from international shipping: burden sharing under different UNFCCC allocation options and regime scenarios. Mar. Policy 35(5), 682-691 (2011).

26 Anderson K, Bows A. Reframing the climate change challenge in light of post-2000 emission trends. Philos. Transact. A Math. Phys. Eng. Sci. 366(1882), 3863-3882 (2008).

27 International Maritime Organization. Main Events in IMO's Work on Limitation and Reduction of Greenhouse Gas Emissions from
International Shipping. International Maritime Organization, London, UK (2011).

28 Nakicenovic N, Davidson O, Davis G et al. IPCC Special Report on Emission Scenarios. Cambridge University Press, Cambridge, UK (2000).

29 Mitropoulos EE. The Long-Serving Secretary-General of the International Maritime Organization (IMO), Mr. Efthimios E. Mitropoulos, looks back at the decisions adopted by the organization during his term. Hellenic Shipping News, Piraeus, Greece (2011).

30 Mander S, Walsh C, Gilbert P, Traut M, Bows A. Decarbonizing the UK energy system and the implications for UK shipping. Carbon Management 3(6), 601-614 (2012).

\section{- Websites}

101 The Guardian. Governments failing to avert catastrophic climate change, IEA warns. www.guardian.co.uk/environment/2012/ apr/25/governments-catastrophic-climatechange-iea

102 International Chamber of Shipping. www.marisec.org/index.html

103 Morooka M. Letter to Christine Lagrande, Managing Director of IMO from the Chair of the International Chamber of Shipping (2012) www.allaboutshipping.co.uk/wp-content/ uploads/2012/07/Letter-to-IMF-from-ICSJuly-2012.pdf 